Chapter 14

\title{
The Pharmacology and Biochemistry of Selenium in Cancer
}

\author{
T. Westermarck, Arno Latvus and Faik Atroshi \\ Additional information is available at the end of the chapter \\ http://dx.doi.org/10.5772/58425
}

\section{Introduction}

Cancer is the leading cause of death in economically developed countries and the second leading cause of death in developing countries $(\mathrm{WHO})^{1}$. It is extraordinarily complex with novel mutations and phenotypes that are often unique to an individual. It is a disease of the chromosomes and the problem is, in almost all cancers, it isn't just one mutation but may be much more. Cancer may be regarded as a complex metabolic deficiency disease [9, $10,11,12,13,14]$

Cancer diet is also used as a complementary approach to cancer that involves the use of special nutritional supplements. Selenium (Se) and cancer is a term that can be referred to the approach or associations between cancer and nutrition that is to lower an individual's risk of cancer. Selenium was first recognized as having some nutritional importance almost six decades ago [15]. Selenium is found in food as selenoamino acids or selenoproteins, and as selenide, selenite, or selenate [16]. Selenium is a critical cofactor in the activity of gluthathione peroxidase and is also important in the management of peroxynitrite. The selenium content of food depends upon soil content and varies regionally and nationally, with soil levels relatively low in most European countries [17, 18, 19]. Soil conditions have been associated with clinical selenium toxicity in animals (selenosis) in some areas with very high selenium content, and with selenium deficiency syndromes in animals and humans in areas of low soil selenium [17].

Selenium is essential nutrient that act as cofactor in enzyme oxidation-reduction reactions (e.g. iodothyronine deiodinase and glutathione peroxidases) [20]. It maintains the specific configuration of proteins, is incorporated into the structure of hormones, and plays a structural and catalytic role in gene expression and transcriptional regulation. The trace element selenium is contained in soil and drinking water varies from area to area, which determines the variation in intake seen in different communities and the amount and chemistry of dietary constituents 
eaten with the this element affect the absorption efficiency of the selenium is said be 'the only trace element to be specified in the genetic code' [21].

Selenocysteine is a vital component of 35 or more selenoproteins, some of which are important enzymes [22]. Selenium functions as a redox centre, an example of which is the reduction of hydrogen peroxide and lipid and phospholipid hydroperoxides to nondamaging water and alcohols by the glutathione peroxidases [23]. Functions of this kind help maintain membrane integrity, and protect prostacyclin production. Prevention of the oxidative chain reactions in this way prevents further damage to lipids, lipoproteins, and DNA; hence its antioxidant function helps prevent atheroma and cancer, among other things [24, 25, 26].

\section{Clinical applications}

Selenium deficiency results in impaired immunity [27], and supplementation is immune stimulant. Deficiency increases the virulence of some viruses such as in Keshan disease [28, 29] by altering their genome to a more virulent one. Deficiency may also be associated with low mood [30], increased cognitive decline in older people, and susceptibility to epilepsy [31], exacerbates hypothyroidism in iodine deficiency [32], protective against cardiovascular disease and cancer $[33,34]$, beneficial in a variety of inflammatory conditions by reducing oxidative stress, and in male fertility [35] through testosterone synthesis and spermatozoa function.

The conventional cancer therapies currently available are surgery, radiotherapy, and chemotherapy. Chemotherapy is typically the main regimen for most cancers. However, many tumours develop resistance to these harsh drugs, known as chemo resistance, which can lead to other complications [36]. A number of natural products and compounds have been shown to act as effective chemo sensitizers. However, taking antioxidants during cancer treatment could interfere with the way chemotherapy work and diminish their benefits to the patient [37]. It was conclude that the use of supplemental antioxidants during chemotherapy and radiation therapy should be discouraged because of the possibility of tumour protection and reduced survival [37].This is because radiation and some chemotherapy agents work by generating free radicals, which then kill rapidly dividing cancer cells. Since antioxidants scavenge free radicals, they might interfere with the therapeutic effects of these treatments. However, oxidation supports the proliferation of malignant cells and may itself interfere with treatment [38]. People who hold this view maintain that antioxidants may counter the harmful effects of oxidation in the malignant process and thereby increase the effects of drugs or radiation therapy to the benefit of the patient. Moreover, they note that some evidence suggests that antioxidant supplements offer patients protection from the toxic effects of therapy [39].

The balance between oxidants and antioxidants can be a key issue in the development of cancer [40] and reactive oxygen species (ROS) are involved in aging, chronic illness, and cancer. Oxidants also cause free radical damage, thus the body generates large amounts of antioxidants to prevent harm and maintain health. However, Watson [41] reported that antioxidants can promote cancer growth of late stage metastatic cancers. The process is explained in terms 
of redox signalling, redox being a term used for reduction and oxidation. Healthy cells and also malignant ones benefit from intact Keap1/Nrf2 signalling, making a dysregulated hydroperoxide signaling a plausible explanation for the increased cancer risk in selenium deficiency [42]. Therefore, a research agenda to investigate the synergistic operation of such substances in cancer treatment is required.

\section{Cancer and oxidation}

Cancer is a generic term for a large group of diseases that can affect any part of the body and it can exist in many different forms and types, some of which are brought on by the destructive choices people make while others are less predictable and are not the result of destructive decisions. It can be broadly grouped into different types (Carcinomas, Sarcomas, Lymphomas and Leukaemia's), depending on which tissues they come from [43, 44]. Cancer develops when cells multiply in the presence of oxidation and other damage. According to micro-evolutionary models, cells become damaged and change their behaviour, growing uncontrollably, and act like the single-celled organisms from which they originally evolved. The cancer cells' individualism overwhelms the cooperative control processes that are essential to a complex multicellular organism [45, 46]. As cancers become malignant, they exhibit incredible genetic diversity. Whereas a benign tumour is like a colony of similar abnormal cells, a malignant tumour is a whole ecosystem. At this late stage, some (but not all) antioxidants can indeed promote cancer cell growth. Thousands of different cell types coexist: cooperating, competing, and struggling to survive. A consequence of the anaerobic conditions that prevail during the early development of a malignancy is that cancer cells differ from healthy cells, in that they have been selected for the way they generate energy (i.e. anaerobically, using glucose) [47, 48].

The sulfhydryl group is the most sensitive to the oxidizing effects of ROS among the amino acid side chains in protein; it is often involved in the intracellular transduction machinery of redox signals in response to physiological and oxidative stimuli. In fact, a variety of biological functions, not directly related to peroxidase activity, have also been reported for the Prx family [49]. Oxidative damage in DNA can cause cancer. Several antioxidant enzymes such as superoxide dismutase, catalase, glutathione peroxidase, glutathione reductase, glutathione Stransferase etc. protect DNA from oxidative stress. It has been proposed that polymorphisms in these enzymes are associated with DNA damage and subsequently the individual's risk of cancer susceptibility [50].

Nutrition and physical activity and major lifestyle changes can reduce the risk of cancer [51, 52]. Antioxidants are becoming an increasingly common choice as a hopeful cancer prevention agent. Importantly, antioxidants limit oxidative damage and thus inhibit early benign cancer growth, preventing cancer from developing. Selenium has received publicity over the past decades based on some confusing and contradictory research about whether low-selenium diets are implicated in cancer risk. To date, this is still a question without a clear answer. However, selenium is required for the proper activity of a group of enzymes collectively called glutathione peroxidase. Each of these enzymes helps to turn toxic hydrogen peroxide into 
harmless water. Of the eight known glutathione peroxidase enzymes, five of them require selenium. It is a necessary component for appropriate function of the immune system, muscle function, successful reproduction, and peak brain function. Also, selenium produces valuable antioxidant enzymes. Deficiencies in selenium have been linked to decreased thyroid function, cardiovascular disease, and cancers [24]. Research shows selenium, especially when used in conjunction with vitamin $\mathrm{C}$, vitamin $\mathrm{E}$ and beta-carotene, works to block chemical reactions that create free radicals in the body (which can damage DNA and cause degenerative change in cells, leading to cancer). Also research has demonstrated that selenium is also linked to reduction in risk to some carcinomas $[6,7]$.

\section{Pathophysiology of cancer and causes}

Cancer is a disease of regulation of tissue growth. In this disease, the cells of the body display uncontrolled growth, invasion that intrudes and destroys adjacent tissues and spreads to other body locations. In order for a normal cell to transform into a cancer cell, genes which regulate cell growth and differentiation must be altered and DNA repair genes are altered and turned off $[53,54]$. The pathophysiology of cancer is a complicated issue. Genes that are influenced in the pathogenesis of cancer are proteins that are involved in a variety of processes including cell growth and differentiation, cell cycle processes, and angiogenesis, which is the formation of new blood vessels [55]. These proteins also play a role in tumour progression, immune regulation, and apoptosis. Since the cells involved are complex and have such a broad range of functions, the pathophysiology of cancer has been hard to determine precisely.

Understanding what causes cancer is a complex process. Cancer has been linked to many factors, such as environmental exposures, lifestyle practices, medical interventions, genetic traits, viruses, familial susceptibility, and aging. Cancer is most probably the result of interactions between repeated carcinogenic exposures and an individual's susceptibility status [56]. Environmental exposures and lifestyle practices have been determined to be the major risk factors in the development of cancer $[57,58]$. The major lifestyle factors that contribute to cancer include smoking, alcohol, diet, medical practices, and ultraviolet exposures.

Genes that are influenced in the pathogenesis of lung cancer are proteins that are involved in a variety of processes including cell growth and differentiation, cell cycle processes, and angiogenesis, which is the formation of new blood vessels. The proteins also play a role in tumour progression, immune regulation, and apoptosis [59, 60]. Since the cells involved are complex and have such a broad range of functions, the pathophysiology of lung cancer has been hard to determine precisely. A healthy cell becomes a cancer cell by undergoing the following processes in which proto-oncogenes are changed to oncogenes. Proto-oncogenes are genes that are coded to maintain normal cell growth. In cases of a developing cancer, oncogene takes its place. Oncogene is a gene that makes cells grow and divide rapidly [61]. Pharmaceutical companies are continuing to develop approaches for targeting oncogene activity in the ongoing war on cancer [61]. Pathology of cancers and other complex disorders have undergone a big change after development of 
technologies like immunohistochemistry, flow cytometry, and molecular biologic approaches to cancer diagnosis. Cancer is not a singular, specific disease but a group of variable tissue responses that result in uncontrolled cell growth [56].

\section{Selenium mechanism}

The biochemistry of selenium differs from other dietary minerals and trace elements. Selenium is not a structural component nor a metal coordination complex and the biosynthesis of selenocysteine is regulated by four genes and begins with the aminoacylation of the amino acid serine by the enzyme serine synthetase to produce Ser-tRNASec [62, 63]. However, selenocysteine is the active site in which, at physiological $\mathrm{pH}$, selenium is fully ionized and is a very efficient redox catalyst [64]. Selenium exists in elemental, organic, and inorganic forms, with four important oxidation states: selenide (Se 2-), elemental ( $\mathrm{Se} 0$ ) selenite $(\mathrm{Se}+4)$, and selenate $(\mathrm{Se}+6)[62,65]$. Selenium compounds inhibit signaling enzymes such as protein kinase $\mathrm{C}(\mathrm{PKC})[66]$ that play crucial roles in tumor promotion. The selenium-containing nutrient, selenomethionine has been shown to regulate the tumor suppresser p53 by the redox factor refl-dependent redox mechanism. Studies continue to support evidence that one important pathway is that many selenium-containing nutrients can be converted in the body to methylselenol. Methylselenol has been shown to block expansion of pre-malignant cells forming into fully developed cancers [67]. Several pathways have been proposed that could explain how selenium-containing compounds could block mutated cells from progressing to cancer. Methylseleninic acid has been shown to inhibit NF-kappa B and regulate I kappa B in prostate cancer cells [68]. Selenium compounds inhibit signaling enzymes such as protein kinase C (PKC) [66] that play crucial roles in tumor promotion. A representative of the hydrogen selenide metabolic pool has been found to protect liver cells against damage to DNA. The cellular redox-milieu involves several metabolic, antioxidative and regulatory aspects that are maintained and regulated largely by two enzyme-based systems: the glutathione and thioredoxin systems [69] The thioredoxin and glutathione systems constitute a balanced redox network. The thioredoxin system may influence virtually all phases of tumorgenesis via its involvement in transcription and translation [69].

There are several possible mechanisms for the protective effect of selenium. Selenium activates an enzyme in the body called glutathione peroxidase that protects against the formation of free radicals - those loose molecular cannons that can damage DNA. There appear to be at least two distinct families of selenium-containing enzymes [70, 71]. The first includes glutathione peroxidases Bermano et al [72] and thioredoxin reductase [73], which are involved in controlling tissue concentrations of highly reactive oxygen-containing metabolites. These metabolites are essential at low concentrations for maintaining cell-mediated immunity against infections but highly toxic if produced in excess.

The role of selenium in the cytosolic enzyme glutathione peroxidase (GPx) was first illustrated $[74,75]$. During stress, infection, or tissue injury, selenoenzymes may protect against the damaging effects of hydrogen peroxide or oxygen-rich free radicals. This family of enzymes 
catalyses the destruction of hydrogen peroxide or lipid hydroperoxides according to the following general reactions:

Selenium-containing glutathione peroxidases (GPx) constitute a family of anti-oxidative enzymes that are capable of reducing organic and inorganic hydroperoxides to the corresponding hydroxy compounds utilizing glutathione or other hydrogen donors as reducing equivalents

$$
\begin{aligned}
& \mathrm{H}_{2} \mathrm{O}_{2}+2 \mathrm{GSH} \cdots \cdots \cdots \cdot \cdots \cdot \mathrm{H}_{2} \mathrm{O}+\mathrm{GSSG} \\
& \mathrm{ROOH}+2 \mathrm{GSH} \cdots \cdots \cdots \cdot \cdot \mathrm{ROH}+\mathrm{H}_{2} \mathrm{O}+\mathrm{GSSG}
\end{aligned}
$$

Where GSH is glutathione and GSSG is its oxidized form. At least four forms of GPx exist; they differ both in their tissue distribution and in their sensitivity to selenium depletion [72]. The GPx enzymes of liver and blood plasma fall in activity rapidly at early stages of selenium deficiency. In contrast, a form of GPx associated specifically with phospholipid-rich tissue membranes is preserved against selenium deficiency and is believed to have broader metabolic roles (e.g., in prostaglandin synthesis) [76]. In concert with vitamin E, selenium is also involved in the protection of cell membranes against oxidative damage. The selenoenzyme thioredoxin reductase is involved in disposal of the products of oxidative metabolism [77]. It contains two selenocysteine groups per molecule and is a major component of a redox system with a multiplicity of functions, among which is the capacity to degrade locally excessive and potentially toxic concentrations of peroxide and hydroperoxides likely to induce cell death and tissue atrophy [76].

There is strong evidence that oxidative free radicals have a role in the development of degenerative diseases including CHD [78]. Oxidative free radicals increase the peroxidation of low density lipoprotein thereby increasing its uptake by macrophages with increased foam cell formation and atherosclerosis [79], though other mechanisms may exist. Anti-oxidants in the diet include vitamin A (carotenoids, which are metabolised to retinol), vitamin C (ascorbate), vitamin E (tocopherol), and selenium, which is an integral part of the antioxidant enzyme glutathione peroxidase:

\section{Selenium function}

Despite an evident progress in cancer diagnosis and treatment, there is a constant need of a drug which could arrest the premalignant process, thus reducing the risk of cancer. However, the role of selenium (Se) as an antioxidant and anticancer agent is well documented [80]. In addition, it has been proven that an adequate concentration of selenium can restore the sensitivity to chemotherapeutic agents of cytostatic-resistant malignant cells [81]. Selenium can exist with oxidation state- $2,+2,+4,+6$, and Se (II) is the dominant form in organoselenium chemistry [82]. The highest activity as a free radical scavenger and anticancer agent is assigned to selenium compounds containing selenium at the +4 oxidation level [83]. Other essential role of selenium in human and animal nutrition is well established. In humans, it has been 
demonstrated that an endemic cardiomyopathy (Keshan disease) prevalent in certain areas of China is correlated with selenium deficiency $[84,85]$. Selenium is often thought to be a dietary antioxidant, but the antioxidant effects of selenium are most likely due to the antioxidant activity of proteins that have this element as an essential component (i.e., selenium-containing proteins), and not to selenium itself [86]. The damage to cells caused by free radicals, especially the damage to DNA, may play a role in the development of cancer and other health conditions [40]. Many observational studies, including case-control studies and cohort studies, have been conducted to investigate whether the use of dietary antioxidant supplements is associated with reduced risks of cancer in humans. Overall, these studies have yielded mixed results [87]. Healthy Chinese men and women at increased risk of developing esophageal cancer and gastric cancer were randomly assigned to take a combination of 15 milligrams (mg) betacarotene, $30 \mathrm{mg} \alpha$-tocopherol, and 50 micrograms $(\mu \mathrm{g})$ selenium daily for 5 years or to take no antioxidant supplements. The initial results of the trial showed that people who took antioxidant supplements had a lower risk of death from gastric cancer but not from oesophageal cancer. However, their risks of developing gastric cancer and/or esophageal cancer were not affected by antioxidant supplementation [88].

As an essential trace element in humans [89], it's only established function is its presence in the enzyme glutathione peroxidase [90]. Using GSH2 as the reducing equivalent, this enzyme plays a significant role in detoxification of peroxides induced by oxygen radicals. As such it may be important in the toxicity of anticancer treatments that generate such reactive molecules [91]. In addition, epidemiological and experimental data suggest an anti-carcinogenic activity by selenium [92]. Considerable epidemiological data suggests that cancer mortality is inversely correlated with selenium consumption. Chemoprotective effect of diphenylmethyl selenocyanate against cyclophosphamide (CP) induced cellular toxicity and antitumor efficacy was evaluated in mice bearing Ehrlich ascites carcinoma [93], their results indicate that diphenylmethyl selenocyanate has the potential to reduce the cellular toxicity of $\mathrm{CP}$ at the same time improving its antitumor efficacy. Supplementation of a torula yeast-based diet with 2.5 or 5.0 ppm Selenium as $\mathrm{Na}_{2} \mathrm{SeO}_{3}$ also significantly increased the survival time of EAT-bearing mice [94]. Their data show that the form and mode of administration of selenium influence the antitumorigenic properties of this trace element. In addition, they suggested that some intermediate in the normal pathway for selenium detoxification is probably responsible for this trace element's antitumorigenic properties [94]. The ability of selenium to inhibit or prevent the growth of Ehrlich as cites tumour cells was highly dependent upon the form and quantity of selenium administered [95]. The only significant alteration that has been observed in mice treated with quantities of selenium at dosages of $4 \mu \mathrm{g} 3$ times weekly was a slight reduction in intestinal weights. The reduction in intestinal weights was not attributable to a reduction in the intestinal macro constituents, suggesting that selenium may have altered rapidly dividing cells [95]. In fact selenocystine was used in the treatment of human leukaemia in 1956 with some short term success $[96,97]$. The mechanism of its effect was thought to be competitive deprivation of cystine, but this was not proven. Others have shown that selenium compounds can cause chromosome breaks and inhibit critical DNA synthetic enzymes [98]. Specific incorporation of selenium into RNA molecules has been observed in several bacterial species. Since in a number of instances modified bases in RNAs have been shown to be involved in regulatory functions of the RNAs, the selenium-modified bases may have similar roles. 
Furthermore, some RNA viruses, as well as leader mRNAs contain RNA-like segments that may interact with specific enzymes and, thus, play regulatory roles [99] Hence, it is reasonable to assume that detailed information concerning selenium-modified RNAs may contribute to the understanding of the biological roles of selenium [100]. Near toxic levels of selenium have been reported to produce tumours in rats but other studies indicated that these concentrations of selenium created chronic toxic hepatitis that resembled hyperplasia.

In mammals glutathione peroxidase is the only selenium-dependent enzyme so far identified, but it seems unlikely that the complicated biological effects of selenium in man and animals are attributable solely to variations in the level of this enzyme. In fact, at least two other seleno proteins of unknown catalytic activity have been detected in animals. Investigations in a variety of animal systems have suggested that there is a significant interaction of selenium with glutathione independent of the enzyme glutathione peroxidase [101]. White muscle disease (WMD), a degenerative muscle disease, found in domestic animals [102, 103]. It is caused by a deficiency of selenium and/or vitamin E. Selenium and vitamin E deficiencies can produce symptoms of ill thrift and reproductive losses: lower conception rates, fetal reabsorption, dystocia, retained placenta, reduced milk production, and reduced semen quality, poor rate of growth or ill thrift in young lambs, low wool yields and have increased incidence of periodontal disease $[102,103]$. Selenium appears to be a key nutrient in counteracting the development of virulence and inhibition of HIV progression to AIDS. It is required for sperm motility and may reduce the risk of miscarriage. Selenium deficiency has been linked to adverse mood states and some findings suggest that selenium deficiency may be a risk factor in cardiovascular diseases [104]. Studies continue to confirm that people with higher levels of selenium in their blood have lower rates of prostate and lung cancers [105].

Selenium is synergistic with vitamin E; they serve related metabolic functions and share in common the role of endogenous antioxidants [106]. Vitamin E has a free radical Scavenger, and Se as a component of the peroxide reducing enzyme, glutathione peroxidase. Vitamin $\mathrm{E}$ restricts the formation of peroxides by neutralizing free radicals, an integral component of glutathione peroxidase, an enzyme responsible for the removal of hydrogen peroxide and organic hydroperoxides [107].

Selenium and vitamin $\mathrm{C} ; \mathrm{CH}_{3} \mathrm{SeH}$ is thought to be a critical metabolite in Se chemoprevention $[108,109]$. The family of selenoenzymes called thioredoxin reductases catalyze the NADPHdependent reduction of oxidized thioredoxin, hyperoxides, dehydroascorbate, ubiquinol and other substrates [110].The action of thioredoxin reductases in recycling dehydroascorbate to ascorbate (vitamin C) now explain the synergistic action of selenium and vitamin C [111]. The thioredoxin system is also capable of regenerating proteins inactivated by ROS. Daily supplementation with vitamin C (120 mg), vitamin E (30 mg), beta-carotene (6 mg), and the minerals selenium $(100 \mu \mathrm{g})$ and zinc $(20 \mathrm{mg})$ for a median of 7.5 years had no effect on the incidence of cancer or cardiovascular disease or on all-cause mortality [112]. Antioxidant and mineral supplementation was associated with lower total cancer incidence and all-cause mortality among men but not among women, and with an increase in skin cancer incidence, including melanoma, among women but not among men [113].

Selenium and Silver; Selenium serves as a major protective factor in precipitating the silver in a highly insoluble and hence inert form of silver selenide. Although some of this may be taken 
up in lysosomes in macrophages, the deposits are essentially long lived or permanent [114]. A lack of positive effect of Se supplementation on the prostate cancer incidence was observed in this study.

\section{Conclusion}

Selenium as non-metals is an essential nutrient that acts as cofactor in enzyme oxidationreduction reactions. It maintains the specific configurations of proteins, is incorporated into the structure of hormones, and plays a structural and catalytic role in gene expression and transcriptional regulation. In the physiological dosage range, Se appears to function as an antimutagenic agent, preventing the malignant transformation of normal cells and the activation of oncogenes. These protective effects of Se seem to be primarily associated with its presence in the glutathione peroxidases, which are known to protect DNA and other cellular components from damage by oxygen radicals. Selenoenzymes are also known to play roles in carcinogen metabolism, in the control of cell division, oxygen metabolism, detoxification processes, apoptosis induction and the functioning of the immune system. Other modes of action, either direct or indirect, may also be operative, such as the partial retransformation of tumor cells and the inactivation of oncogenes.

\section{Author details}

T. Westermarck ${ }^{1 *}$, Arno Latvus $^{2}$ and Faik Atroshi ${ }^{3}$

*Address all correspondence to: tuomas.westermarck@ppa.inet.fi

1 Rinnekoti Research Center, Espoo, Finland

2 Hankintatukku Oy, Museokatu, Helsinki, Finland

3 Pharmacology \& Toxicology, University of Helsinki, Finland

\section{References}

[1] WHO, World Health Organization. The Global Burden of Disease: 2004 Update. Geneva: World Health Organization; 2008.

[2] Meyskens, F. L., Jr., \& Szabo, E. Diet and cancer: the disconnect between epidemiology and randomized clinical trials. Cancer Epidemiol Biomarkers Prev, 2005, 14(6), 1366-1369. 
[3] Bjelakovic, G; Nikolova, D; Gluud, LL; Simonetti, RG; Gluud, C (2012). "Antioxidant supplements for prevention of mortality in healthy participants and patients with various diseases". In Bjelakovic, Goran. Cochrane database of systematic reviews (Online) 3: CD007176.

[4] Imlay JA. Pathways of oxidative damage. Annu Rev Microbiol. 2003;57:395-418.

[5] Rayman MP. Food-chain selenium and human health. Br J Nutr. 2008;100:254-268.

[6] Clark LC, Combs GF Jr, Turnbull BW, Slate EH, Chalker DK, Chow J, Davis LS, Glover RA, Graham GF, Gross EG, Krongrad A, Lesher JL Jr, Park HK, Sanders BB Jr, Smith CL, Taylor JR. Effects of selenium supplementation for cancer prevention in patients with carcinoma of the skin. A randomized controlled trial. Nutritional Prevention of Cancer Study Group. JAMA. 1996 Dec 25;276(24):1957-63.

[7] Clark LC, Jacobs ET. Environmental selenium and cancer: risk or protection? Cancer Epidemiol Biomarkers Prev. 1998 Oct;7(10):847-8.

[8] Combs G.F. Selenium in global food systems. Br. J. Nutr. 2001;85:517-547.

[9] Tallberg T, Westermarck T, Atroshi F. Cancer Treatment, Based on Active Nutritional Bio-Modulation, Hormonal Therapy and Specific Autologous Immunotherapy.In: Heavy Metals in the Environment (editors: Zueng-Sang Chen, Dar-Yuan Lee, TserSheng Lin). Publisher, National Taiwan UniversityTaipei, Taiwan.

[10] DeBerardinis RJ. Is cancer a disease of abnormal cellular metabolism? New angles on an old idea. Genet Med. 2008 Nov;10(11):767-77.

[11] Anand P, Kunnumakkara AB, Kunnumakara AB, Sundaram C, Harikumar KB, Tharakan ST, Lai OS, Sung B, Aggarwal BB (September 2008). "Cancer is a preventable disease that requires major lifestyle changes". Pharm. Res. 25 (9): 2097-116.

[12] Seyfried TN, Shelton LM. Cancer as a metabolic disease. Nutr Metab (Lond). 2010 Jan 27;7:7. doi: 10.1186/1743-7075-7-7.

[13] Tallberg, T and Atroshi F. Prostate Cancer, the Long Search for Etiologic and Therapeutic Factors: Dietary Supplementation Avoiding Invasive Treatment. In: Prostate Cancer - From Bench to Bedside, 33-52, 2011.

[14] Crohns M, Westermarck T and Atroshi F. Prostate Cancer, Inflammation and Antioxidants. In :Advances in Prostate Cancer. (Gerhard Hamilton, ed.), 2013, INTECH Publisher, Croatia. 978-953-51-0932-7.

[15] Schwarz, K., and C. M. Foltz. 1957. Se as an integral part of factor against dietary liver degeneration. J. Am. Chem. Society 79:3292-3296.

[16] Sunde RA. Regulation of glutathione peroxidase-1 expression. In: Hatfield DL, Berry MJ, Gladyshev VN, editors. Selenium: its molecular biology and role in human health. 2nd ed. New York: Springer Science Media; 2006. p. 149-60. 
[17] Kabata-Pendias A. Geochemistry of selenium. J Environ Pathol Toxicol Oncol. 1998;17(3-4):173-7.

[18] Haug A, Graham RD, Christophersen OA, Lyons GH. How to use the world's scarce selenium resources efficiently to increase the selenium concentration in food. Microb Ecol Health Dis. 2007 Dec;19(4):209-228.

[19] Sioen, I., Boon, P.E., Huybrechts, I. et al. (2010) Long-term dietary exposure to selenium in young children living in different European countries. Scientific Report submitted to EFSA.

[20] Kraus RJ, Prohaska JR, Ganther HE. Oxidized forms of ovine erythrocyte glutathione peroxidase. Cyanide inhibition of a 4-glutathione:4-selenoenzyme. Biochim Biophys Acta. 1980 Sep 9;615(1):19-26.

[21] Hatfield DL, Gladyshev VN. How selenium has altered our understanding of the genetic code. Mol Cell Biol. 2002 Jun;22(11):3565-76.

[22] Johansson L, Gafvelin G, Arnér ES. Selenocysteine in proteins-properties and biotechnological use. Biochim Biophys Acta. 2005 Oct 30;1726(1):1-13.

[23] Stadtman TC. Discoveries of vitamin B12 and selenium enzymes. Annu Rev Biochem. 2002;71:1-16.

[24] Rayman MP. The importance of selenium to human health.Lancet. $2000 \mathrm{Jul}$ 15;356(9225):233-41.

[25] Donovan J, Copeland PR. The efficiency of selenocysteine incorporation is regulated by translation initiation factors. J Mol Biol. 2010 Jul 23;400(4):659-64.

[26] Bjelakovic G, Nikolova D, Gluud LL, Simonetti RG, Gluud C. Antioxidant supplements for prevention of mortality in healthy participants and patients with various diseases. Cochrane Database Syst Rev. 2012 Mar 14;3:CD007176. doi: 10.1002/14651858.CD007176.pub2.

[27] Arthur JR, McKenzie RC, Beckett GJ. Selenium in the immune system. J Nutr. 2003 May;133(5 Suppl 1):1457S-9S.

[28] Diplock AT. Metabolic and functional defects in selenium deficiency. Philos Trans R Soc Lond B Biol Sci. 1981 Aug 14;294(1071):105-17.

[29] Chen X. Selenium and cardiomyopathy (Keshan disease). Acta Pharmacol Toxicol (Copenh). 1986;59 Suppl 7:325-30.

[30] Hawkes WC, Hornbostel L. Effects of dietary selenium on mood in healthy men living in a metabolic research unit. Biol Psychiatry. 1996 Jan 15;39(2):121-8.

[31] Majkowski J, Atroshi F, Westermarck T. Effects of Epileptic Seizures and Antiepileptic Drugs on Oxygen Stress. Factors Attenuating the Effects of Oxygen Stress. EPILEPTOLOGY 2011, 19:143-157. 
[32] Zimmermann MB, Köhrle J. The impact of iron and selenium deficiencies on iodine and thyroid metabolism: biochemistry and relevance to public health. Thyroid. 2002 Oct;12(10):867-78.

[33] Whanger PD. Selenium and its relationship to cancer: an update.Br J Nutr. 2004 Jan; 91(1):11-28.

[34] Aboul-Fadl T. Selenium derivatives as cancer preventive agents. Curr Med Chem Anticancer Agents. 2005 Nov;5(6):637-52.

[35] Hansen JC, Deguchi Y. Selenium and fertility in animals and man--a review. Acta Vet Scand. 1996;37(1):19-30.

[36] Gupta D, Raina V, Rath GK, Shukla NK, Mohanti BK, Sharma DN. Clinical and pathological response rates of docetaxel-based neoadjuvant chemotherapy in locally advanced breast cancer and comparison with anthracycline-based chemotherapies: eight-year experience from single centre. Indian J Cancer. 2011 Oct-Dec;48(4):410-4.

[37] Lawenda BD, Kelly KM, Ladas EJ, Sagar SM, Vickers A, Blumberg JB. Should supplemental antioxidant administration be avoided during chemotherapy and radiation therapy? J Natl Cancer Inst. 2008 Jun 4;100(11):773-83. doi: 10.1093/jnci/djn148. Epub 2008 May 27.

[38] Borek C, Ong A, Mason H. In vitro transformation of human cells by radiation. Toxicol Ind Health. 1987 Sep;3(3):397-404.

[39] Casciari JJ, Riordan NH, Schmidt TL, Meng XL, Jackson JA, Riordan HD. Cytotoxicity of ascorbate, lipoic acid, and other antioxidants in hollow fibre in vitro tumours. Br J Cancer. 2001 Jun 1;84(11):1544-50.

[40] Valko M, Rhodes CJ, Moncol J, Izakovic M, Mazur M. Free radicals, metals and antioxidants in oxidative stress-induced cancer. Chem Biol Interact. 2006;160:1-40.

[41] Watson J. Oxidants, antioxidants and the current incurability of metastatic cancers. Open Biol. 2013 Jan 8;3(1):120144.

[42] Brigelius-Flohé R, Kipp AP. Selenium in the redox regulation of the Nrf2 and the Wnt pathway. Methods Enzymol. 2013;527:65-86.

[43] Cancer Research UK "How many different types of cancer are there? CancerHelp UK". Retrieved 11 May 2012.

[44] Lebeau A, Kriegsmann M, Burandt E, Sinn HP. [Invasive breast cancer: the current WHO classification]. Pathologe. 2014 Feb;35(1):7-17. doi: 10.1007/s00292-013-1841-7.

[45] Hanahan, D ; Weinberg, R A. (2011). "Hallmarks of Cancer: The Next Generation". Cell 144 (5): 646-74. 
[46] Danaei G, Vander Hoorn S, Lopez AD, Murray CJ, Ezzati M (2005). "Causes of cancer in the world: comparative risk assessment of nine behavioural and environmental risk factors". Lancet 366 (9499): 1784-93

[47] Warburg O. On the origin of cancer cells. Science. 1956 Feb 24;123(3191):309-14.

[48] Villalba M, Rathore MG, Lopez-Royuela N, Krzywinska E, Garaude J, Allende-Vega N. From tumor cell metabolism to tumor immune escape. Int J Biochem Cell Biol. 2013 Jan;45(1):106-13.

[49] Butterfield LH, Merino A, Golub SH, Shau H. From cytoprotection to tumor suppression: the multifactorial role of peroxiredoxins. Antioxid Redox Signal. 1999 Winter; 1(4):385-402.

[50] Asim M, Khan LA, Husain SA, Husain S, Sarma MP, Ahmad I, Sharma JK, Sharma A, Sharma S, Thayumanavan L, Kar P. Genetic polymorphism of glutathione S transferases M1 and T1 in Indian patients with hepatocellular carcinoma.Dis Markers. 2010;28(6):369-76.

[51] Doyle C, Kushi LH, Byers T, Courneya KS, Demark-Wahnefried W, Grant B, McTiernan A, Rock CL, Thompson C, Gansler T, Andrews KS. Nutrition and physical activity during and after cancer treatment: an American Cancer Society guide for informed choices. CA Cancer J Clin. 2006 Nov-Dec;56(6):323-53.

[52] Anand P, Kunnumakkara AB, Sundaram C, Harikumar KB, Tharakan ST, Lai OS, Sung B, Aggarwal BB. Cancer is a preventable disease that requires major lifestyle changes. Pharm Res. 2008 Sep;25(9):2097-116.

[53] Braig M, Schmitt CA. Oncogene-induced senescence: putting the brakes on tumor development. Cancer Res. 2006 Mar 15;66(6):2881-4.

[54] Baylin SB, Ohm JE. Epigenetic gene silencing in cancer-a mechanism for early oncogenic pathway addiction? Nat Rev Cancer. 2006 Feb;6(2):107-16.

[55] Suzuki H, Asakawa A, Amitani H, Fujitsuka N, Nakamura N, Inui A. Cancer cachexia pathophysiology and translational aspect of herbal medicine. Jpn J Clin Oncol. 2013 Jul;43(7):695-705. doi: 10.1093/jjco/hyt075. Epub 2013 Jun 4.

[56] Fraumeni JF Jr. Epidemiologic approaches to cancer etiology. Annu Rev Public Health. 1982;3:85-100.

[57] Chlebowski RT. Reducing the risk of breast cancer. N Engl J Med. 2000 Jul 20;343(3): 191-8.

[58] Lichtenstein GR. Reduction of colorectal cancer risk in patients with Crohn's disease. Rev Gastroenterol Disord. 2002;2 Suppl 2:S16-24.

[59] Wick, M., Dubey, P., Koeppen, H., Siegel, C. T., Fields, P. E., Chen, L., Bluestone, J. A., Schreiber, H. Antigenic cancer cells grow progressively in immune hosts without evidence for T cell exhaustion or systemic anergy J. Exp. Med. 1997,186,229-238. 
[60] Rosenberg, S. A. Progress in human tumour immunology and immunotherapy Nature, 2001, 411,380-384.

[61] Chin L, Gray JW. Translating insights from the cancer genome into clinical practice. Nature. 2008 Apr 3;452(7187):553-63. doi: 10.1038/nature06914.

[62] Rotruck JT, Pope AL, Ganther HE, Swanson AB, Hafeman DG and Hoekstra WG. Selenium: biochemical role as a component of glutathione peroxidase. Science $1973 \mathrm{Feb}$ 9;179(73):588-90.

[63] Leinfelder, W., Forchhammer, K., Veprek, B., et al., In vitro synthesis of selenocysteinyl-tRNA (UCA) from seryl-tRNA (UCA): involvement and characterization of the selD gene product. Proc. Natl. Acad. Sci. USA 1990:87;543-547.

[64] Reddy CC, Massaro EJ. Biochemistry of selenium: a brief overview. Fundam Appl Toxicol. 1983 Sep-Oct;3(5):431-6.

[65] Stadtman TC. SELENIUM BIOCHEMISTRY. Annu. Rev. Biochem. 1990. 59:111-127.

[66] Gopalakrishna R, Gundimeda U. Antioxidant regulation of protein kinase C in cancer prevention. J Nutr. 2002 Dec;132(12):3819S-3823S.

[67] Zeng H, Cheng WH, Johnson LK. Methylselenol, a selenium metabolite, modulates p53 pathway and inhibits the growth of colon cancer xenografts in Balb/c mice. J Nutr Biochem. 2013 May;24(5):776-80.

[68] Pillai SS, Sugathan JK, Indira M. Selenium downregulates RAGE and NFкB expression in diabetic rats. Biol Trace Elem Res. 2012 Oct;149(1):71-7.

[69] Gromer S., Arscott L.D., Williams C.H., Jr, Schirmer R.H., Becker K. Human placenta thioredoxin reductase. Isolation of the selenoenzyme, steady state kinetics, and inhibition by therapeutic gold compounds. J. Biol. Chem. 1998, 273:20096-20101.

[70] Chu FF. "The human glutathione peroxidase genes GPX2, GPX3, and GPX4 map to chromosomes 14, 5, and 19, respectively". Cytogenet Cell Genet, 1994, 66 (2): 96-8.

[71] Müller C, Wingler K, Brigelius-Flohé R. "3'UTRs of glutathione peroxidases differentially affect selenium-dependent mRNA stability and selenocysteine incorporation efficiency". Biol. Chem, 2003,384 (1): 11-8.

[72] Bermano G, Arthur JR, Hesketh JE. Role of the 3' untranslated region in the regulation of cytosolic glutathione peroxidase and phospholipid-hydroperoxide glutathione peroxidase gene expression by selenium supply. Biochem J. 1996 Dec 15;320 (Pt 3):891-5.

[73] Lacey BM, Eckenroth BE, Flemer S, Hondal RJ. Selenium in thioredoxin reductase: a mechanistic perspective. Biochemistry. 2008 Dec 2;47(48):12810-21. 
[74] Mills GC. Hemoglobin catabolism. I. Glutathione peroxidase, an erythrocyte enzyme which protects hemoglobin from oxidative breakdown. J Biol Chem. 1957 Nov; 229(1):189-197.

[75] Ganther HE, Kraus RJ. Oxidation states of glutathione peroxidase. Methods Enzymol. 1984;107:593-602.

[76] Maiorino M, Chu FF, Ursini F, Davies KJ, Doroshow JH, Esworthy RS. Phospholipid hydroperoxide glutathione peroxidase is the $18-\mathrm{kDa}$ selenoprotein expressed in human tumor cell lines. J Biol Chem. 1991 Apr 25;266(12):7728-32.

[77] Arteel GE, Sies H. The biochemistry of selenium and the glutathione system. Environ Toxicol Pharmacol. 2001 Sep;10(4):153-8.

[78] Ames. B N, Shigenaga MK, and Hagen TM. Oxidants, antioxidants, and the degenerative diseases of aging. Proc. Natl. Acad. Sci. USA,1993, 90:7915-7922.

[79] Aviram, M. (1995) Oxidative modification of low density lipoprotein and its relation to atherosclerosis. Isr. J. Med. Sci. 31:241-249.

[80] Tapiero H, Townsend DM, Tew KD. The antioxidant role of selenium and selenocompounds. Biomed Pharmacother. 2003 May-Jun;57(3-4):134-44.

[81] Jönsson-Videsäter K, Björkhem-Bergman L, Hossain A, Söderberg A, Eriksson LC, Paul C, Rosén A, Björnstedt M. Selenite-induced apoptosis in doxorubicin-resistant cells and effects on the thioredoxin system. Biochem Pharmacol. 2004 Feb 1;67(3): 513-22.

[82] Wallschläger D, Feldmann J. Formation, occurrence, significance, and analysis of organoselenium and organotellurium compounds in the environment. Met Ions Life Sci. 2010;7:319-64. doi: 10.1039/BK9781847551771-00319. Epub 2010 Jan 30.

[83] Suchocki P, Misiewicz I, Skupinska K, Waclawek K, Fijalek Z, Kasprzycka-Guttman $\mathrm{T}$. The activity of Selol in multidrug-resistant and sensitive human leukemia cells. Oncol Rep. 2007 Oct;18(4):893-9.

[84] Beck MA, Levander OA, Handy J (May 2003). "Selenium deficiency and viral infection". J. Nutr. 133 (5 Suppl 1): 1463S-7S. PMID 12730444.

[85] Ren LQ, Li XJ, Li GS, Zhao ZT, Sun B, Sun F (November 2004). "Coxsackievirus B3 infection and its mutation in Keshan disease". World J. Gastroenterol. 10 (22): 3299302.

[86] Davis CD, Tsuji PA, Milner JA. Selenoproteins and cancer prevention. Annu Rev Nutr. 2012 Aug 21;32:73-95.

[87] Patterson BH, Levander OA. Naturally occurring selenium compounds in cancer chemoprevention trials: a workshop summary. Cancer Epidemiol Biomarkers Prev. 1997 Jan;6(1):63-9. 
[88] Blot WJ, Li JY, Taylor PR, Guo W, Dawsey S, Wang GQ, Yang CS, Zheng SF, Gail M, Li GY, et al. Nutrition intervention trials in Linxian, China: supplementation with specific vitamin/mineral combinations, cancer incidence, and disease-specific mortality in the general population. J Natl Cancer Inst. 1993 Sep 15;85(18):1483-92.

[89] Young VR. Selenium: a case for its essentiality in man. N Engl J Med. 1981 May 14;304(20):1228-30.

[90] Hafeman DG, Sunde RA, Hoekstra WG. Effect of dietary selenium on erythrocyte and liver glutathione peroxidase in the rat. J Nutr. 1974 May;104(5):580-7.

[91] Batist G, Norton J, Katki AG, Wagman L, Ferrans VJ, Maher M, Myers CE. Cardiac and red blood cell glutathione peroxidase: results of a prospective randomized trial in patients on total parenteral nutrition. Cancer Res. 1985 Nov;45(11 Pt 2):5900-3.

[92] Schrauzer GN. Selenium and cancer: a review. Bioinorg Chem. 1976;5(3):275-81.

[93] Chakraborty P, Sk UH, Bhattacharya S. Chemoprotection and enhancement of cancer chemotherapeutic efficacy of cyclophosphamide in mice bearing Ehrlich ascites carcinoma by diphenylmethyl selenocyanate. Cancer Chemother Pharmacol. 2009 Oct; 64(5):971-80. doi: 10.1007/s00280-009-0950-8. Epub 2009 Feb 17.

[94] Poirier KA, Milner JA. Factors influencing the antitumorigenic properties of selenium in mice. J Nutr. 1983 Nov;113(11):2147-54.

[95] Greeder GA, Milner JA. Factors influencing the inhibitory effect of selenium on mice inoculated with Ehrlich ascites tumor cells. Science. 1980 Aug 15;209(4458):825-7.

[96] Weisberger, A. S.. and Suhrland, L. G. Studies on analogues of L-cysteine and L-cystine. The effect of selenium cystine on leukemia. Blood, / /: 19-30, 1956.

[97] Batist G, Katki AG, Klecker RW Jr, Myers CE. Selenium-induced cytotoxicity of human leukemia cells: interaction with reduced glutathione. Cancer Res. 1986 Nov; 46(11):5482-5.

[98] Weitberg AB, Weitzman SA, Clark EP, Stossel TP. Effects of antioxidants on oxidantinduced sister chromatid exchange formation. J Clin Invest. 1985 Jun;75(6):1835-41.

[99] Hendrickson W.A., Horton,J.R. and LeMaster,D.M. (1990) Selenomethionyl proteins produced for analysis by multiwavelength anomalous diffraction (MAD): a vehicle for direct determination of three-dimensional structure. EMBO J., 9, 1665-1672.

[100] Ching WM. Characterization of selenium-containing tRNAGlu from Clostridium sticklandii. Arch Biochem Biophys. 1986 Jan;244(1):137-46.

[101] Chung AS, Maines MD. Effect of selenium on glutathione metabolism. Induction of gamma-glutamylcysteine synthetase and glutathione reductase in the rat liver. Biochem Pharmacol. 1981 Dec 1;30(23):3217-23. 
[102] Lagace A. Effect of selenium on white muscle disease in lambs.J Am Vet Med Assoc. 1961 Feb 15;138:188-90

[103] Schwarz S. Essentiality and metabolic functions of selenium. Med Clin North Am. 1976 Jul;60(4):745-58.

[104] Ferencík M, Ebringer L. Modulatory effects of selenium and zinc on the immune system. Folia Microbiol (Praha). 2003;48(3):417-26.

[105] Vogt TM, Ziegler RG, Graubard BI, Swanson CA, Greenberg RS, Schoenberg JB, Swanson GM, Hayes RB, Mayne ST. Serum selenium and risk of prostate cancer in U.S. blacks and whites. Int J Cancer. 2003 Feb 20;103(5):664-70.

[106] Hoekstra, W. G. Biochemicalfunction of seleniumand its relation to vitamin E. Fed. Proc., 34: 2083-2089,1975.

[107] Tappel AL. Biological antioxidant protection against lipid peroxidation damage. Am J Clin Nutr. 1970 Aug;23(8):1137-9.

[108] Ip C. Interaction of Vitamin C and Selenium Supplementation in the Modification of Mammary Carcinogenesis in Rats. JNCI J Natl Cancer Inst (1986) 77 (1): 299-303.

[109] Spallholz JE, Palace VP, Reid TW (2004) Methioninase and selenomethionine but not Se-ethylselenocysteine generate methylselenol and superoxide in an in vitro chemiluminescent assay: implications for the nutritional carcinostatic activity of selenoamino acids. Biochem Pharmacol 67:547-554.

[110] Stadtman TC. Selenium biochemistry. Mammalian selenoenzymes. Ann N Y Acad Sci. 2000;899:399-402.

[111] Badmaev V, Majeed M, Passwater RA. Selenium: a quest for better understanding. Altern Ther Health Med. 1996 Jul;2(4):59-62, 65-7.

[112] Hercberg S, Galan P, Preziosi P, Bertrais S, Mennen L, Malvy D, Roussel AM, Favier A, Briançon S. The SU.VI.MAX Study: a randomized, placebo-controlled trial of the health effects of antioxidant vitamins and minerals. Arch Intern Med. 2004 Nov 22;164(21):2335-42.

[113] Hercberg S, Kesse-Guyot E, Druesne-Pecollo N, Touvier M, Favier A, Latino-Martel $\mathrm{P}$, Briançon S, Galan P. Incidence of cancers, ischemic cardiovascular diseases and mortality during 5-year follow-up after stopping antioxidant vitamins and minerals supplements: a postintervention follow-up in the SU.VI.MAX Study. Int J Cancer. 2010 Oct 15;127(8):1875-81.

[114] Sato S, Sueki H, and Nishijima A. "Two unusual cases of argyria: the application of an improved tissue processing method for X-ray microanalysis of selenium and sulphur in silver-laden granules," British Journal of Dermatology, vol. 140, no. 1, pp. 158-163, 1999. 
